\title{
Aspectos jurídicos do turismo e hospitalidade no Brasil: a existência de marcos regulatórios para o setor
}

\author{
Nilzo Felisberto - Mestre em Direito. Faculdade de Tecnologia Senac Criciúma - Brasil. nilzo@prof.sc.senac.br. \\ Naíra Ronconi Fernandes - Graduanda em Processos Gerenciais. Faculdade de Tecnologia Senac Criciúma - Brasil. nairaronconi@gmail.com.
}

\section{RESUMO}

O Brasil, por ser rico em belezas naturais e outros atrativos, é destino turístico do mundo, e, desse modo, urge por normas que regulamentem a exploração de todo o seu patrimônio ambiental e cultural, bem como estabeleçam medidas protetivas ao turista consumidor. Discutida e debatida de forma superficial pelos organismos nacionais afins e pelos operadores do direito, as recentes legislações pátrias que tratam das atribuições governamentais, planejamento, desenvolvimento e estímulo ao setor do turismo e hospitalidade buscam disciplinar, desde a prestação de serviços, o cadastramento, a classificação e a fiscalização do setor, em favor do empreendedor e proteção ao consumidor dessa modalidade de bem e serviço. Pesquisa de natureza documental, o objetivo é descrever e analisar o setor de turismo e hospitalidade, a partir dos marcos regulatórios existentes para o setor no Brasil, com base em suas formas de normalização e certificação. Diante da relevância temática, o estudo constituise de abordagem interdisciplinar entre área do turismo, hospitalidade e o direito. Conclui-se, ao observar o ordenamento jurídico como um todo composto das particularidades do setor, em que normas constitucionais e infraconstitucionais, além de determinantes das portarias e normas regulamentadoras específicas, figuram como verdadeiros sustentáculos e colunas legalizadoras das atividades deste setor - não como algo independente e isolado dos demais setores da economia, que, assim como eles, têm cumprido sua missão e muito há por evoluir.

Palavras-chave: Direito. Legislação. Normalização. Turismo e Hospitalidade.

\section{Legal aspects of tourism and hospitality in Brazil: the existence of regulatory frameworks for the sector}

\begin{abstract}
Brazil, for being rich in natural beauty and other attractions, is one of the tourist destination in the world, and thus, it is urgent that further regulation governing the exploration of all its environmental and cultural heritage be established, as well as rules with protective measures for the consumer tourist. Discussed and debated only superficially by national bodies and by law enforcement officers, the existing legislation, which deals with government functions, planning, development and stimulating the tourism and hospitality sector, is seeking to discipline all aspects of the process, from service delivery, to registration, classification and supervision of the sector, in favor of the entrepreneur and protection of the consumer of this area of the goods and service industry. This is a research of documentary nature its goal is to describe and analyze the tourism and hospitality industry, based on the existing regulatory framework for the sector in Brazil, and its forms of standardization and certification. Given the relevance of the theme, an interdisciplinary approach between the tourism and hospitality laws was followed. By observing the legal system as a whole made up of the particularities of the sector, we concluded that constitutional and infra-constitutional norms, laws and regulatory standards, appear as true legislating pillars and legislating cornerstones of the activities of this sector - not as something independent, isolated from other sectors of the economy and which, like those other sectors, has run its course, yet with room for improvement.
\end{abstract}

Keywords: Law. Legislation. Regulation. Tourism and Hospitality. 


\section{INTRODUÇÃO}

Por vezes, falar sobre o direito nos remeterá a diversas formas e concepções, posto que a chamada ciência jurídica é detentora das mais variadas compreensões, linhas de pensamento e matizes. Todavia, há que se considerar essas diversas escolas do direito, como disciplinas apartadas, mas que, a todo o momento, se interligam e se conectam compondo um todo lógico e perfeito.

O turismo e hospitalidade se trata de um importante setor da economia nacional, regulamentado por legislações específicas e esparsas que, ao longo dos anos, vem aprimorando-se como o próprio setor em tela que, como setor da economia, encontra-se vinculado a outros tantos setores da atividade econômica, o veremos devidamente interconectado com outros segmentos do ordenamento jurídico.

Esse flagrante dualismo precisa sempre ser observado, uma vez que a regulamentação de hotéis, resorts, campings e outros meios de hospedagem tem por mister proteger e informar, por um lado, especificamente o consumidor. Entretanto, sobre o mesmo ordenamento jurídico existem normas que podem ser aplicadas aos empreendedores de turismo e hospitalidade, bem como, por outro lado, aos não turistas, além de outras normas que não as da hospitalidade e turismo que podem ser aplicadas a todos os envolvidos nessa dinâmica teia.

De acordo com Badaró (2006), toda a legislação pertinente ao setor precisa ser entendida como um ramo do próprio direito, dado a essas diversas interligações que ora se interconectam de forma imprescindível e complementar, ora se desprendem, ressaltando apenas as suas peculiaridades.

De toda forma, tem-se por concreto que, assim como o ordenamento jurídico é um todo composto de particularidades, o setor de turismo e hospitalidade não é algo independente e isolado dos demais setores da economia, não podendo contar com regulamentos que muito o favoreça, nem muito lhe onere.

Sendo o Brasil um país riquíssimo em belezas naturais e em diversos outros atrativos que ao serem explorados pela atividade turística clamam por regulamentação a fim de resguardar o próprio setor e seus clientes.

Com efeito, faz-se necessária a existência de normas que regulamentem a exploração, de forma que, por um lado, se tem todo esse patrimônio ambiental que urge por medidas protetivas, ao turista, que soma, a cada dia, um número maior de indivíduos, precipuamente pelas facilidades de locomoção e hospedagem hoje proporcionadas e pela globalização que, de certa forma, acaba por incitar essas pessoas a desejarem conhecer o mundo, a vivenciarem culturas diferentes.

Como consequência dessa "evolução turística", passa a ser de extrema importância que existam normas jurídicas de proteção de pessoas, que deixam suas casas para encontrarem o desconhecido, lugares que nunca passaram, utilizando muitas vezes diversos meios de transporte com facilidades ou dificuldades de acesso. Também há de se mencionar a necessidade de atendimento em postos médicos, em caso de eventuais acidentes.

Em suma, quando o turista deixa sua casa, está, na maioria das vezes, confiando no que lhe foi passado pela agência e agentes de viagens. Além disso, devem estar protegidos, igualmente, os locais a serem comercialmente explorados, de forma que a fauna, a flora e construções de valor histórico ou artístico não sejam prejudicadas pela atividade turística.

Ainda que superficialmente discutida e debatida pelos diversos organismos nacionais afins ao setor de hospedagem e turismo, como também pelos operadores do direito, as recentes legislações pátrias que tratam do tema e que definem as atribuições governamentais no que diz 
respeito ao planejamento, desenvolvimento e estímulo ao setor turístico e hospitalidade buscam disciplinar desde a prestação de serviços, o cadastramento, a classificação e a fiscalização do setor em favor do empreendedor e em proteção ao consumidor desta modalidade de bem e serviço.

Faz-se mister destacar a clara opção constitucional do Estado Democrático de Direito brasileiro em estimular e valorizar a convivência harmoniosa dos diversos níveis existentes na pirâmide legislativa posto que, se de um lado centraliza a produção legal sob a égide da constitucionalidade, por outro lado determina e autoriza a organização e controle do setor produtivo mediante a produção de normas regulamentadoras e certificadoras.

No Brasil, vigora como valor absoluto a supremacia da ordem constitucional, de modo que as normas constitucionais, por serem obra do poder constituinte originário, encontram-se em patamar de superioridade em relação às demais leis, sendo o fundamento de validade de todas as demais normas e regulamentos.

Em respeito à hierarquia constitucional, as normas encontram-se separadas em três grupos distintos: as normas constitucionais, as infraconstitucionais (as leis) e as normas infralegais - todas existem mediante competente processo legislativo, nos três níveis da federação, ou seja, União, Estados e Municípios, conforme a competência temática definida no próprio texto constitucional. Assim, as normas infraconstitucionais detalham a Constituição Federal, e as normas infralegais detalham, explicam e regulamentam a aplicação prática das leis. Desse modo, torna-se evidente a existência de hierarquia entre os grupos e a não existência de hierarquia entre as normas de um mesmo grupo. As normas constitucionais estão em nível hierárquico superior às normas infraconstitucionais - aqui encontraremos as leis, os decretos, as medidas provisórias, as resoluções e os tratados e convenções internacionais e essas por sua vez, são hierarquicamente superiores às normas infralegais - aqui se encontrarão dispostas as normas nascidas da burocracia administrativa, entre elas as normatizações e as certificações regulamentadas pela administração pública para organizar a ela própria e aos setores produtivos da economia (LENZA, 2009).

Por normatização, entende-se o processo financeiro, organizacional e humano, mas que não se resume à padronização de procedimentos, mas que propicia às organizações envolvidas, o planejamento necessário para enfrentar a concorrência ou, ao menos, estar ao mesmo nível dela. $\mathrm{E}$, por certificação, teremos como um processo no qual determinada organização é declarada, por órgão competente, em atendimento às normas técnicas atinentes ao setor (LENZA, 2009).

Tendo isso presente, o objetivo deste estudo é analisar o setor de turismo e hospitalidade a partir dos marcos regulatórios existentes para o setor no Brasil, com base em suas formas de normalização e certificação. Metodologicamente, adota-se a técnica de pesquisa bibliográfica e documental, visto que se pretende analisar leis, normas e certificações, assim como suas interrelações. Conforme citado, as leis, normas e certificações relacionam-se e completam-se. Aqui, notadamente, as Leis no 8.078/90, no 10.683/2003 e n० 11.771/2008; as Portarias no 387/2007 e $n^{\circ}$ 312/2013; e as normas regulamentadoras e certificadoras NBR $n^{\circ} 15.333 / 2007$, a NBR $n^{\circ}$ 17.021/2011 e a Nit-Dicor-051.

\section{CONTEXTO HISTÓRICO DO DIREITO DO TURISMO BRASILEIRO}

Ao longo do tempo, o turismo e a hospitalidade começam a se destacar no país, tornandose necessário criar órgãos para regulamentação e fiscalização da atividade. Toda a regulamentação do setor é um marco importante, pois se imaginarmos o país, não apenas no ramo hoteleiro, mas em qualquer outra atividade, sem a existência de regras ou normativas, não poderíamos saber a 
quem delegar responsabilidades, entre consumidores e prestadores de serviços, de modo a estabelecer um equilíbrio social.

De acordo com Ré (2007), como qualquer outro serviço, a hospitalidade e o turismo podem afetar a estabilidade pública e social. Por isso, a importância da intervenção do estado para a regulamentação e fiscalização do setor.

Nesse contexto, é fundada a Associação Brasileira da Indústria de Hotéis (ABIH), em 1936, que até os dias atuais é o órgão responsável por dar suporte à manutenção da fiscalização do setor hoteleiro. Mais tarde, o novo regulamento do sistema de classificação instituiu aos meios de hospedagem, critérios para obter o uso de símbolos e estrelas, que são classificados de acordo com as condições de conforto que possuem.

Segundo Badaró (2014), foi a partir de 1938 que o Estado passou a notar o crescimento e a importância das atividades turísticas em solo brasileiro. Sendo nessa época que se começou a editar leis regulamentadoras do setor.

Nesse sentido, conheceremos o Decreto-Lei no 406/38, de 4 de maio de 1938, promulgado pelo presidente Getúlio Vargas, que permitiu a exploração da atividade turística, a venda de passagens aéreas, entre outras medidas. E, dois anos após teremos, em 23 de julho de 1940, a edição do Decreto-Lei no 2440/40, que estabelece as condições e permite o funcionamento das agências e empresas de viagens de turismo.

A partir de 1958, de acordo com Badaró (2014), começaram a surgir instituições brasileiras de turismo, sob o Decreto no 44863/58, a Comissão Brasileira de Turismo (COMBRATUR), o DecretoLei no 55/66, a Empresa Brasileira de Turismo (EMBRATUR) e o Fundo Geral de Turismo (FUNGETUR) criados em 1971, e, em 1974, cria-se o Fundo de Investimento Setorial de Turismo (FISET).

Em 1982, o Decreto no 87348 permitiu a criação do serviço de transporte terrestre turístico. Já em 1993, foi criada pela Lei no 8623/93, a profissão de Guia de Turismo. Em 2002, nasceu o Instituto Brasileiro de ciências e Direito do Turismo (IBCDTur), uma instituição não governamental voltada ao desenvolvimento do turismo no Brasil e na América Latina (BADARÓ, 2014).

O turismo até 1988 não tinha previsões ou análises em sede constitucional, pois não contava com o intervencionismo do Estado, nem mesmo com investimentos do setor privado. Depois do período de restrições das liberdades democráticas enfrentadas pelo país, o setor teve seu ingresso nas previsões constitucionais.

A partir dessa data, começou-se a pensar que um hotel não é apenas um local para dormir, mas sim um meio de hospedagem para aqueles que buscam conhecer novos lugares, cidades, culturas. Em razão do avanço do território ocupado pelas redes de turismo e a falta de pessoas para regulamentar, instalou-se a atividade turística por meio da infraestrutura básica e, inicialmente, desprovida de regulação ou regulamentação (RÉ, 2007).

\subsection{O tratamento constitucional do turismo}

Pode-se conceituar turismo como um deslocamento de pessoas cuja finalidade é o lazer, o descanso, a aventura, a cultura, circunstâncias tais que fazem uma pessoa deixar seu ambiente natural e procurar, por um determinado espaço de tempo, um ambiente que ofereça condições para a satisfação do objetivo visado (BADARÓ, 2014).

É assim que a Constituição Federal vigente trouxe em seu título VII “Da Ordem Econômica e Financeira", dispositivo expresso no sentido de que cabe à União, Estados, Distrito Federal e Municípios promover e incentivar o turismo como fator de desenvolvimento social e econômico.

Badaró (2014) salienta que a Constituição da República trouxe o turismo, em 1988, ao maior plano de ordem jurídica brasileira, que diz no Art. 180 - "A União, os Estados, o Distrito 
Federal e os Municípios promoverão e incentivarão o turismo como fator de desenvolvimento social e econômico" (BRASIL, 1988).

O referido dispositivo constitucional observa três elementos balizadores da atividade turística, que são:

a) Elevação do turismo à condição de fator de desenvolvimento social e econômico.

b) Promoção estatal do turismo.

c) Incentivo estatal do turismo.

Nesse sentido e esclarecendo o objetivo do dispositivo constitucional, Nieto (2004, p. 36) destaca que

a Constituição é a lei maior do país, não podendo nenhuma outra norma contrariar os preceitos ali contidos. Sendo assim, é de extrema importância o completo entendimento dos princípios constitucionais atinentes ao turismo, verdadeiros norteadores de toda a disciplina jurídica aplicada ao setor.

O cumprimento do texto constitucional configura-se em irremediável valor republicano das garantias do Estado Democrático de Direito, cujo abandono não caracterizaria apenas e tão somente uma agressão à Carta Maior, mas uma agressão à cidadania e ao cidadão.

Nesse prisma, Longanese (2004, p. 10), destaca dois desses elementos balizadores mencionados anteriormente:

Com base no princípio da promoção e no do incentivo ao turismo cabe ao Estado criar condições para o crescimento das atividades turísticas no Brasil, propiciando meios para estimular essa atividade, utilizando-se de instrumentos como a redução da carga tributária das empresas dos setores turístico e hoteleiro, assim como a concessão de linhas de crédito, por meio dos bancos oficiais e privados, que propiciem o crescimento desse segmento industrial, principalmente com a criação de novos polos turísticos no Brasil.

Como se vê, o turismo pressupõe a busca pelo bem-estar. É momento em que problemas e frustrações tendem a ser deixados de lado, dando lugar ao descanso físico e mental, visando a busca de qualidade de vida. A partir deste breve regimento jurídico encontra proteção e elevo constitucional, tanto do ponto de vista das pessoas como do setor econômico.

\section{A REGULAMENTAÇÃO LEGAL VIGENTE NO BRASIL}

Muito embora tratar-se de um jovem setor da economia nacional, o turismo exige regulamentação básica e essencial como forma de estabelecer limites, organização e responsabilidades para todos os envolvidos.

Esse processo de regulamentação é um processo dinâmico, assim como a sociedade humana, assim como o setor em elevo neste artigo.

\subsection{A Lei nº 6505/77}

A Lei no 6505/77 permitiu também ao Instituto Brasileiro de Turismo (EMBRATUR), classificar as categorias turísticas, levando em conta, como critério de avaliação, o conforto, preços, serviços etc (BRASIL, 1977). 
Depois de classificados, cabe ao Ministério do Turismo a certificação aos prestadores de serviço turístico. Isso faz com que, não apenas, o turista tenha defesa e proteção, mas também as empresas do setor turístico (BADARÓ, 2014).

Mamede $(2001$, p. 29) "recomenda cuidado ao intérprete, visto que constituída à sombra de um texto constitucional intervencionista, devendo ser recepcionada por um novo sistema constitucional que, como visto, realça a livre iniciativa e a livre concorrência".

Nesse sentido, a livre iniciativa que se encontra albergada na proteção constitucional não é tão livre assim, mas uma iniciativa vigiada e regulada o que, por si só, não pode se configurar em algo danoso aos atores envolvidos nesse processo.

\subsection{A Lei 8181/91}

Criada em 1991, a Lei no 8181/91 diz que é de total responsabilidade da EMBRATUR, hoje Ministério do Turismo, "cadastrar as empresas, classificar os empreendimentos dedicados às atividades turísticas e exercer função fiscalizadora, nos termos da Legislação vigente" (BADARÓ, 2014, p. 8).

Badaró (2014) afirma ainda que o maior desafio do setor turístico está na fiscalização dos empreendimentos, visando estabelecer um ambiente público em acordo com as normas jurídicas, sendo que o papel reservado às instituições estatais de gerenciamento turístico não interfira no crescimento dos estabelecimentos turísticos.

Com isso, Mamede (2001, p. 36) destaca que "não é uma questão de planejar ou definir políticas estratégicas, mas a repercussão direta do poder de fiscalizar empreendimentos". O Estado tem o poder de influenciar todas as atividades do setor turístico, mas, dependendo do grau de interesse público, pode ajudar ou prejudicar o crescimento do empreendimento no qual se busca atingir.

\subsection{A Lei no 10683/03: a criação do Ministério do Turismo}

A Lei no 10683/03, criou, em 2003, o Ministério do Turismo, a saber:

a) Política nacional de desenvolvimento do turismo; b) promoção e divulgação do turismo nacional, no país e no exterior; c) estímulo às iniciativas públicas e privadas de incentivo às atividades turísticas; d) planejamento, coordenação, supervisão e avaliação dos planos e programas de incentivo ao turismo; e) gestão do Fundo Geral do Turismo; f) desenvolvimento do Sistema Brasileiro de Certificação e Classificação das atividades, empreendimentos e equipamentos dos prestadores de serviços turísticos. (BADARÓ, 2014, p. 14).

Badaró (2014, p. 16) ressalta que "o Ministério do Turismo, para consecução de seus objetivos, conta com os seguintes órgãos: Conselho Nacional do Turismo, Secretaria de Políticas de Turismo e Secretaria de Programas de Desenvolvimento do Turismo".

Dessa forma, percebe-se uma ampla articulação nacional que objetiva dar sustentação às políticas de fomento para o setor; todavia, o Ministério do Turismo não detém poder absoluto no ordenamento do setor, desenvolvendo apenas e tão somente a função de orientação e desenvolvimento.

Nessa direção, Badaró (2007, p. 13) fala sobre a existência de um certo consenso entre diversos autores ao afirmarem que 
é preciso redobrado cuidado na aplicação das regras que criam exigências para o cadastro e sua manutenção. Assim, a exigência de atendimento permanente aos padrões mínimos de conforto, serviços estabelecidos e a apresentação, em tempo oportuno de informações, estatísticas, relatórios, balanços e demonstrações financeiras, conforme for estabelecido pelo Ministério.

Destarte, o ato de instituição, ao estabelecer determinados requisitos de funcionamento desse setor, ao determinar e/ou permitir sua exploração econômica, não poderá jamais afrontar o importante dispositivo constitucional que consagra a livre iniciativa como valor nacional e republicano.

Na compreensão de Mamede (2001), não se configura em flagrante de limitação ao exercício da atividade econômica, no estabelecimento de requisitos para a organização do setor produtivo e sua posterior classificação governamental, sem imposição de tal medida a todos indistintamente e apenas àqueles que se interessem por tal chancela estatal. Estes sim, deverão submeter-se aos padrões técnicos mínimos, razoável e proporcionalmente estabelecidos com a finalidade de elevação dos níveis qualitativos de fornecimento dos serviços.

De acordo com Ré (2007, p. 9), a intervenção do Ministério do Turismo se dá no sentido de classificação, normatização e fiscalização, mas aponta certos entraves ao concluir que nos

deparamos com a dificuldade do exercício das ações fiscalizadoras, nos termos dos decretos vigentes. Isso faz-nos perceber que a regulamentação desse setor mostra-se como uma verdadeira colcha de retalhos, denotando, assim, a fragilidade do planejamento do setor turístico e, por conseguinte, hoteleiro no Brasil, onde a representatividade dos organismos do setor é reduzida e sua legitimação é oriunda de atos administrativos.

Na compreensão de Mamede (2001), não se configura em flagrante de limitação ao exercício da atividade econômica, e tão somente no estabelecimento de requisitos para a organização do setor produtivo e sua posterior classificação governamental, não impondo tal medida a todos indistintamente e apenas àqueles que se interessem por tal chancela estatal estes sim deverão submeter-se aos padrões técnicos mínimos, razoável e proporcionalmente estabelecidos com a finalidade de elevação dos níveis qualitativos de fornecimento dos serviços.

\subsection{A Lei n 11771/08: a Nova Lei do Turismo}

Oliveira $(2009$, p. 7) lembra que "a lei do turismo chega ao Brasil em um momento crucial de reestruturação da atividade no país", visto que ela representa o acúmulo estratégico de quase uma década de planos e de esforços organizativos do setor.

Com 47 artigos dispostos em 6 Capítulos (Das Disposições Preliminares; Da Política, do Plano e do Sistema Nacional de Turismo; Da Coordenação e Integração de Decisões e Ações no Plano Federal; Do Fomento à Atividade Turística; Dos Prestadores de Serviços Turísticos e Das Disposições Finais), a lei em apreço, de acordo com sua ementa, dispõe sobre a Política Nacional de Turismo, define as atribuições do Governo Federal no planejamento, desenvolvimento e estímulo ao setor turístico, e dá outras providências - revogando outros dispositivos do ordenamento infraconstitucional em sua totalidade ou apenas em parte de alguns.

Nesse sentido, observamos a inteligência do art. $21^{\circ}$ da Lei no $11.771 / 08$ :

Art. 21. Consideram-se prestadores de serviços turísticos, para os fins desta Lei, as sociedades empresárias, sociedades simples, os empresários individuais e os serviços sociais autônomos que prestem serviços turísticos remunerados e que 
exerçam as seguintes atividades econômicas relacionadas à cadeia produtiva do turismo: I - meios de hospedagem; II - agências de turismo; III - transportadoras turísticas; IV - organizadoras de eventos; V - parques temáticos; e VI acampamentos turísticos (BRASIL, 2008).

Ao criar a Política Nacional de Turismo, a lei estabelece os formatos e modalidades para a classificação do turismo como atividade econômica, estabelecendo benefícios fiscais e creditícios para as agências de turismo, meios de hospedagem (hotéis, pousadas e diversas), bem como para os organizadores de feiras e congressos.

$\mathrm{O}$ art. $5^{\circ}$ da referida Lei traz os objetivos da Política Nacional de Turismo:

A Política Nacional de Turismo tem por objetivos: I - democratizar e propiciar o acesso ao turismo no País a todos os segmentos populacionais, contribuindo para a elevação do bem-estar geral; II - reduzir as disparidades sociais e econômicas de ordem regional, promovendo a inclusão social pelo crescimento da oferta de trabalho e melhor distribuição de renda; [...] (BRASIL, 2008).

Como o próprio título diz, não há o que comentar sobre algo local ou distrital, há que se destacar o caráter da abrangência nacional da política pública estabelecida pela lei e, dessa forma, exige um esforço nacional (a União, os Estados e os Municípios) em sua consecução. Vale considerar que, caso um dos entes enumerados se furte de sua missão, tal política tenderá à inércia e indignação.

\subsection{A Legislação correlata: Código das Relações de Consumo}

Trata-se do Código das Relações de Consumo, decretado pela Lei n 8078, que busca obter harmonia entre clientes e fornecedores.

Por intermédio da Lei n 8078/90, também conhecida como Código de Defesa do Consumidor (CDC), surgiram os direitos básicos do consumidor, garantindo ao consumidor obter proteção contratual, direito da qualidade e todas as informações sobre o serviço ou produto a ser adquirido (BADARÓ, 2014).

Tendo em vista a natureza da prestação de serviço envolvendo o turismo e hospitalidade, difícil se torna uma classificação do contrato que rege tal relação. Isso porque tal modalidade de contrato possui diversos elementos que, muitas vezes, fogem ao controle da principal parte contratante, qual seja, a agência de turismo, que firma uma série de outros contratos com terceiros (empresas de transporte, de hospedagem, alimentação, casas de espetáculo e assim por diante), para que o "pacote turístico" contratado seja cumprido.

Diante dessas considerações preliminares, sendo o contrato de turismo um contrato que contém diversos núcleos de prestação de serviços, alguns princípios aplicáveis são pertinentes à modalidade contratual, qual sejam: (1) princípio da qualidade: garante ao consumidor direito de receber um produto/serviço de qualidade; (2) ausência da qualidade por defeito ou periculosidade: não trazer qualquer prejuízo à saúde, integridade física ou ao interesse patrimonial ao consumidor; (3) princípio da transparência: dá o direito do consumidor ser informado sobre a qualidade, quantidade, composição e características do produto ou serviço; (4) princípio da proteção contratual: nos artigos 46 a 54 do Código de Defesa do Consumidor, está previsto que se não lhe foi comunicado sobre o contrato, o consumidor está ausente de qualquer obrigação que Ihe foi gerada. E, mesmo diante da ocorrência de dúvidas, prevalece o entendimento mais favorável ao consumidor (BADARÓ, 2014). 
Ainda que de forma rasa, fazem-se necessárias algumas considerações acerca das espécies de regramento jurídico que são passíveis de serem aplicadas na relação de consumo existente na modalidade de prestação de serviço em apreço, posto que, de acordo com parte da doutrina, o contrato que se configura em tal relação pode estar amparado por dois tipos diferentes de normas que serão aplicadas a depender da lesão sofrida pelo contratante: o regramento do inadimplemento contratual do Código Civil e o Código de Defesa do Consumidor.

Com efeito, é de plena aplicação ao caso o Código de Defesa do Consumidor, visto que se trata de pessoa física ou jurídica que utiliza um serviço oferecido, merecendo a proteção trazida pelo Código.

De acordo com Badaró (2014, p. 32),

havendo dúvida quanto à interpretação de cláusula contratual, prevalece o entendimento mais favorável ao consumidor. Foi previsto o direito de rescisão contratual, sem que o consumidor venha a arcar com nenhuma despesa, dentro do prazo de sete dias a contar de sua assinatura ou do ato do recebimento do produto ou serviço, mas somente se o adquiriu fora do estabelecimento comercial, por exemplo, por telefone ou em domicílio.

Vale ressaltar algumas exigências do código de defesa ao consumidor para que se possa cumprir na prática, devendo as empresas ofertar seus bens e serviços de modo que fique claro ao consumidor a compra de qualquer produto ou serviço. Desta forma, o consumidor deverá receber informações na língua portuguesa, a respeito de preços e formas de pagamentos.

\section{NORMALIZAÇÃO E CERTIFICAÇÃO EM TURISMO E HOSPITALIDADE NO BRASIL: RELAÇÕES HIERÁRQUICAS E LEGISLATIVAS}

As normas começaram a surgir no período da revolução industrial pela necessidade de crescimento na comercialização de produtos.

De acordo com Perez (2006), em um ambiente altamente globalizado em que as organizações de turismo e hospitalidade estão inseridas, há um significativo acirramento competitivo, não apenas no ambiente interno de um país, bem como nas relações exteriores.

Objetivando aperfeiçoar a utilização dos recursos disponíveis e aumentar a competitividade nesse setor da economia, são necessárias a criação e a utilização de normas técnicas visando as melhorias dos serviços ofertados, além da otimização de recursos e esforços.

Segundo Lavor (2009, p. 38), "a palavra 'norma' pode transmitir uma ideia de 'regra que se deve seguir' e, por isso, muitas vezes existe a compreensão erronia de que uma norma tem a validade de uma regulamentação ou legislação". No Brasil, foi criada, em 1940, a Associação Brasileira de Normas Técnicas (ABNT), cuja responsabilidade é fazer a regulamentação das normas no país.

Segundo Fernandes e Santos (2006, p. 2), a normalização é uma atividade que "busca a qualificação de produtos e serviços, de maneira organizada e padronizada, que o homem, através de necessidades sociais, usou de sua criatividade para racionalizar e normalizar situações incômodas, causando sérios problemas no cotidiano".

Os referidos autores destacam que se torna extremamente problemático quando a normalização não ocorre de forma sistemática e habitual, quando cada interessado apresenta formas e critérios que não seguem padrões. Assim sendo, urge o estabelecimento de um padrão, a ABNT. 
A simples criação e estabelecimento de normas técnicas, por vezes, não produzem qualquer efeito ou os efeitos esperados. Fazem-se necessários uma orquestração e envolvimento dos interessados de forma a produzir um ambiente de propositiva credibilidade à norma disposta e sua aplicabilidade. Nesse sentido, para o Ministério do Turismo:

O processo de normalização é dinâmico e envolve a participação de diversas partes nela interessada, incluindo as empresas envolvidas na cadeia de fornecimento, os consumidores, os institutos de pesquisa e universidades, o governo e outros eventuais interessados nos resultados da normalização como os trabalhadores e os representantes das comunidades envolvidas (BRASIL, 2005, p. 26).

Quando o assunto é a normalização internacional o cronograma dos procedimentos é um pouco mais severo, pois, para que se possa criá-las, é necessária uma demanda por parte dos especialistas, de algum Organismo Nacional de Normalização (ONN). No turismo, por exemplo, é identificada a demanda por uma estrutura de estudo na International Organization for Standardization (ISO), para a execução das normas internacionais.

Após a identificação da demanda, a ISO analisa dois pontos: a pertinência do assunto e a existência de outros grupos que estejam debatendo o assunto.

Voltados ainda ao turismo, a Associação Espanhola de Normalização e Certificação (AENOR) e o Instituto Nacional da Normalização e da Propriedade Intelectual (INNORPI) normalizam a proposta de criação de uma nova estrutura de estudo e buscam a aceitação de outros países membros da ISO.

Seguindo essa mesma ordem, foi criado em 2005 o Comitê Técnico TC 228 - "Turismo e Serviços Relacionados". Desse comitê fazem parte 64 países; 53 deles são membros P (com direito a voto) e 11 são membros $\mathrm{O}$ (sem direito a voto, são apenas observadores).

Com essa conformação programática, podemos ressaltar que o processo de normalização envolve todos os participantes para que as normas correspondam às características e procedimentos no qual estão inseridas.

Lavor (2009, p. 40) diz que "as normas elaboradas podem contribuir para uma melhor sustentabilidade ambiental, econômica, entre outros, o que é uma tarefa complexa devido ao grande número de elementos a serem considerados".

No MERCOSUL, o órgão responsável pela gestão da normalização é a Associação Mercosul da Normalização (AMN), que tem como objetivo beneficiar a integração e cooperação de todos os membros envolvidos, buscando a harmonia entre os países participantes.

No setor turístico, após aprovação da AMN, o Comitê Setorial Mercosul de Turismo (CSM 23), órgão responsável pela normalização no campo do turismo, estabelece os programas de normalização.

As normas aplicadas no Mercosul são automaticamente adotadas como normas nacionais por seus membros o que significa que se tornam também normas brasileiras (NBR).

No Brasil, o processo de normalização é feito de forma democrática, ou seja, envolve diversas partes criadas a partir de uma demanda da sociedade e não por um órgão normalizador, justificando a fundação do Comitê Técnico denominado de TCs.

Em 2002, foi fundado o Comitê Brasileiro de Normalização em Turismo (CB 54), pela Associação Brasileira de Normas Técnicas, que tem como finalidade planejar, coordenar e controlar as normas turísticas.

O processo de normalização no Brasil apresenta como princípio a necessidade de ser democrático e participativo, isto é, envolver as diversas partes interessadas, 
tais como fornecedores, produtores, consumidores, institutos de pesquisas, governo, dentre outros. Esses atores deverão participar da criação das normas, que serão baseadas em consenso, após ampla discussão. (LAVOR, 2009, p. 46).

No Brasil, as entidades envolvidas na normalização e certificação do turismo são a ISO, ABNT, INMETRO e os organismos certificadores. É concedido um certificado para as empresas do setor turístico quando a empresa encontra-se de acordo com as normas exigidas para a realização dos trabalhos no setor turístico, analisando tanto sua estrutura quanto sua credibilidade no mercado.

A ISO, de acordo com Lavor (2009, p. 49), "é uma organização não governamental, que ao contrário do sistema das Nações Unidas, não possui membros de delegações de governos nacionais". Além disso, destaca-se como uma importante organização dentre os setores públicos e privados, pois seus governantes podem atuar em ambos os setores.

Os membros da ISO são os Institutos de Normalização nacionais com maior representatividade em seus países, sendo estabelecido apenas um membro por país. Cada "membro efetivo" tem direito a um voto independentemente da dimensão e da força econômica de seu país. Os "membros correspondentes" pagam taxas reduzidas e podem participar de qualquer corpo técnico como observador, sem direito a voto. Os "membros assinantes" também pagam taxas reduzidas e são institutos de países com uma enconomia de pequena representação, mas que querem manter contato com a normalização internacional. (LAVOR, 2009, p. 50).

No setor turistico, a ISO cita pelo TC 228, a norma ISO 18513:2003, que trata da terminologia usada no setor. Além disso, existem outras seis normas relacionadas ao turismo, nos requisitos mínimos de segurança no treinamento de mergulhadores.

A ABNT é um orgão fundador da ISO que contribuiu na criação da Comissão Panamericana de Normas Técnicas (COPANT) e participa também na elaboração da Associação MERCOSUL de Normalização (AMN). A ABNT também vem trabalhando, desde 1950, no desenvolvimento de diversos programas para suprir as necessidades das empresas brasilerias.

O INMETRO é o Instituto Nacional da Metrologia, Normalização e Qualidade Industrial. Cabe ao INMETRO, segundo Lavor (2009, p. 52), a "tarefa de harmonizar os diferentes interesses dos diversos segmentos da sociedade". Podemos afirmar também que, ao longos dos anos, o instituto vem ganhando confiança de seus clientes, pela sua credibilidade.

De acordo com o Ministério do Turismo, "a certificação é a constatação da necessidade de nivelar a qualidade dos produtos, serviços e sistemas de gestão" (BRASIL, 2005). Perseguir tais medidas pode melhorar a imagem da organização, bem como facilitar a decisão de compra para clientes e consumidores.

Em especial, o turismo e hospitalidade, diante de suas particularidades e especificidades que envolvem diversas variáveis, conjugáveis ou não, e que vão desde a escolha de um destino, as acomodações de um hotel e um rol de serviços oferecidos (alimentação), o procedimento de certificação ocupa lugar central.

Diferentemente das situações ordinárias de consumo, ao turismo acrescenta-se o fato de que o consumidor, geralmente, tem a necessidade de realizar escolhas à distância, uma vez que ele se desloca de seu ambiente para outro ao qual não pertence e, sendo assim, existe a necessidade de garantias com relação ao produto ou serviço que está sendo adquirido. (LAVOR, 2009. p. 55). 
A existência de certificações em diversos setores de turismo e hospitalidade estabelece uma série de garantias ao consumidor, visto que a liberdade de escolha deste se encontre consignada à conformidade e segurança entre seu desejo e o produto ou serviço ofertado.

No Brasil, para que a certificação aconteça, é necessário que haja norma e organismo de certificação e acreditação, e, como dito anteriormente, tais normas e organismos já existem em solo pátrio. Como organismo de acreditação, temos convencionado o INMETRO.

A acreditação é atestada de terceira parte relacionada a um organismo de avaliação de conformidade, comunicando a demonstração formal da sua competência para realizar tarefas específicas de avaliação de conformidade. No INMETRO é de caráter voluntário e representa o reconhecimento formal da competência de um organismo de Avaliação da Conformidade - OAC para desenvolver tarefas específicas, segundo requisitos estabelecidos. (INMETRO, 2009).

Há que se ressaltar que a acreditação é concedida mediante o cumprimento de protocolos internacionais reconhecidos pelo Sistema Brasileiro de Certificação (SBC) e que, por sua vez, em se tratando de sistemas de gestão, se encontram baseados nos pertinentes códigos do International Accreditation Forum (IAF).

Lavor (2009) destaca que, em relação aos produtos e serviços do turismo e hospitalidade, existem alguns documentos que regulamentam tais serviços, como: a Portaria no 387, de 23 de outubro de 2007 - que estabelece o Regulamento de Avaliação da Conformidade para Sistema de Gestão da Sustentabilidade nos Meios de Hospedagem, e o NIT-DICOR-Y como Critério para Acreditação de Organismos de Certificação de Sistemas de Gestão da Sustentabilidade dos Meios de Hospedagem, sendo de ambos o Brasil signatário.

Os critérios têm por base os valores de tratamento impessoal e isonômicos, não devendo servir como instrumento de favorecimento ou de perseguição de quem quer que seja, sendo esses critérios para o turismo e hospitalidade parte integrante dos chamados regulamentos de Avaliação de Conformidade (RAC).

Avaliar a conformidade significa verificar se os produtos, materiais, serviços, sistemas, processos ou pessoas estão em conformidade com as especificações de uma determinada norma. Diversos produtos e serviços precisam passar por essa avaliação antes de serem comercializados (LAVOR, 2009, p. 57).

Os procedimentos desenvolvidos nas chamadas Avaliações de Conformidade têm destacado alguns objetivos, a saber: (1) informar e proteger o consumidor; (2) propiciar a concorrência justa; (3) estimular a melhoria de forma contínua da qualidade; (4) facilitar o comércio internacional; (5) fortalecer o mercado interno (LAVOR, 2009).

Desta feita, para alcançar seus objetivos, trilhando o caminho da credibilidade, faz se necessário que as Avaliações de Conformidade sejam feitas de forma isenta e transparente, trabalhando com os diversos interesses envolvidos sem se deixar envolver por eles.

No entendimento de Lavor (2009), é mister gizar que o próprio setor de turismo e hospitalidade, em tempos pretéritos já passou por essa experiência, por meio dos sistemas de "selos de classificação" e que por ter sido feito de forma equivocada acabou por cair em descrédito, posto que o empreendedor discordava da classificação estabelecida, quando não tentava abrir um caminho de "negociação" com os avaliadores, buscado submeter como válida a sua autoavaliação.

Há um antigo ditado que diz que levamos anos para construir uma relação de confiança e que, em apenas alguns minutos, por uma atitude equivocada ou inconveniente esta se desfaz. Por isso, é importante para os consumidores que os setores econômicos envolvidos tomem 
consciência da importância de empenharem confiança nos programas de Avaliação de Conformidade no sentido de cumprir e fazer cumprir os objetivos das ACs citados anteriormente.

O Brasil, destaque turístico do mundo inteiro, não pode deixar de observar tais princípios, normas e guias internacionais destinados ao crescimento interno, considerando os programas de Avaliação de Conformidade para reconhecimento de organismos internacionais.

Algumas normas e portarias já conformam e regulamentam às ACs no turismo e hospitalidade brasileira, a saber:

1) A ABNT NBR ISO/IEC 17021 - requisitos de auditoria interna e certificação de sistema de gestão.

2) NIT-DICOR-051 - critérios de acreditação de organismos de certificação de sistemas de gestão de segurança para turismo de aventura.

3) Portaria no 228/2006 - regulamento de avaliação de conformidade para sistemas de gestão de segurança para turismo de aventura.

4) NBR 15333 - meios de hospedagem - sistemas de gestão de sustentabilidade requisitos de competência - aplicável às organizações que necessitam realizar auditorias internas ou externas em seus sistemas de gestão de sustentabilidade em meios de hospedagem.

Por fim, torna-se flagrante perceber que no Brasil a normalização e a certificação busca cumprir um procedimento ritual estruturado e funcional orientado para o bom atendimento local e com viéses de observação do cenário internacional no que diz respeito ao turismo.

À guisa de complementar o presente estudo, faz-se míster apresentar de forma organizada essa propalada inter-relação entre as leis e as normas regulamentadoras do setor, devidamente acompanhadas de breve notas explicativas, conforme Quadro 1.

Quadro 1 - Leias e normas regulamentadoras

\begin{tabular}{|c|c|c|}
\hline \multicolumn{2}{|l|}{ Legislação Federal } & \multirow[b]{2}{*}{$\begin{array}{c}\text { Instruções Normativas, Regulamentos, } \\
\text { Portarias (ementa) }\end{array}$} \\
\hline Dispositivo Legal & Finalidade (ementa) & \\
\hline $\begin{array}{l}\text { Lei } \mathrm{n}^{\circ} 8.078 \text {, de } 11 \text { de } \\
\text { setembro de } 1990 \\
\text { (BRASIL, 1990). }\end{array}$ & $\begin{array}{l}\text { Dispõe sobre a proteção } \\
\text { do consumidor e dá } \\
\text { outras providências. }\end{array}$ & $\begin{array}{l}\text { NBR 17.021/2011 - Norma técnica com vinculação à } \\
\text { qualificação dos serviços e equipamentos turísticos e ao } \\
\text { estabelecimento dos requisitos de avaliação da } \\
\text { conformidade para Classificação de Meios de } \\
\text { Hospedagem, visando a orientar o consumidor na } \\
\text { escolha de um meio de hospedagem, coerente com suas } \\
\text { expectativas pautadas em aspectos ligados à qualidade } \\
\text { das instalações, dos serviços prestados e à } \\
\text { sustentabilidade do empreendimento. }\end{array}$ \\
\hline $\begin{array}{l}\text { Lei } n^{\circ} 10.683 \text {, de } 28 \\
\text { de maio de } 2003 \\
\text { (BRASIL, 2003). }\end{array}$ & $\begin{array}{l}\text { Cria o Ministério do } \\
\text { Turismo, entre outros }\end{array}$ & $\begin{array}{l}\text { Portaria 228/2006 - Regulamento de Avaliação da } \\
\text { Conformidade para Sistema de Gestão da Segurança em } \\
\text { Turismo de Aventura. } \\
\text { Portaria 100/2011 - Institui o Sistema Brasileiro de } \\
\text { Classificação de Meios de Hospedagem (SBClass), } \\
\text { estabelece os critérios de classificação destes, cria o } \\
\text { Conselho Técnico Nacional de Classificação de Meios de } \\
\text { Hospedagem (CTClass) e dá outras providências. } \\
\text { NIT-DICOR-051, de abril de } 2014 \text { - Estabelece o } \\
\text { procedimento para testemunhar o desempenho do } \\
\text { organismo de certificação na execução de sua atividade. } \\
\text { Define critérios de acreditação de organismos de } \\
\text { certificação de sistemas de gestão de segurança para }\end{array}$ \\
\hline
\end{tabular}




\begin{tabular}{|c|c|c|}
\hline & & $\begin{array}{l}\text { turismo de aventura. } \\
\text { NBR 17021/2011 - A norma contém princípios e } \\
\text { requisitos para a competência, coerência e } \\
\text { imparcialidade da auditoria e certificação de sistemas de } \\
\text { gestão de todos os tipos (por exemplo, sistemas de } \\
\text { gestão da qualidade ou sistemas de gestão ambiental) e } \\
\text { para os organismos que oferecem essas atividades. Os } \\
\text { grganismos de certificação que operam de acordo com } \\
\text { esta Norma não precisam oferecer todos os tipos de } \\
\text { certificação de sistemas de gestão. }\end{array}$ \\
\hline $\begin{array}{l}\text { Lei no } 11.771 \text {, de } 17 \\
\text { de setembro de } 2008 \\
\text { (BRASIL, 2008). }\end{array}$ & $\begin{array}{l}\text { Dispõe sobre a Política } \\
\text { Nacional de Turismo, } \\
\text { define as atribuições do } \\
\text { Governo Federal no } \\
\text { planejamento, } \\
\text { desenvolvimento e } \\
\text { estímulo ao setor } \\
\text { turístico; revoga a Lei no } \\
\text { 6.505, de } 13 \text { de } \\
\text { dezembro de 1977, o } \\
\text { Decreto-Lei n } 2.294, \text { de } \\
21 \text { de novembro de 1986, } \\
\text { e dispositivos da Lei nº } \\
\text { 8.181, de } 28 \text { de março de } \\
\text { 1991; e dá outras } \\
\text { providências (BRASIL, } \\
\text { 1991). }\end{array}$ & $\begin{array}{l}\text { Portaria 387/2007 - Considerando que o turismo } \\
\text { sustentável visa assegurar a viabilidade dos destinos e } \\
\text { empreendimentos em longo prazo, além de contribuir } \\
\text { para a promoção do desenvolvimento econômico e } \\
\text { social, para a proteção do meio ambiente e da } \\
\text { diversidade cultural, estabelece o regulamento de } \\
\text { Avaliação da Conformidade para Sistema de Gestão da } \\
\text { Sustentabilidade para Meios de Hospedagem. } \\
\text { - Portaria no } 312 / 2013 \text { - Estabelece as regras e condições } \\
\text { a serem observadas pelos prestadores de serviços de } \\
\text { transporte turístico de superfície terrestre nacional e } \\
\text { internacional. } \\
\text { - NBR 15333, de } 23 \text { de abril de } 2007 \text { - Esta norma } \\
\text { estabelece os requisitos aplicáveis para a competência de } \\
\text { auditores de sistemas de gestão da sustentabilidade - } \\
\text { meios de hospedagem. }\end{array}$ \\
\hline
\end{tabular}

Fonte: Elaborado pelos autores (2016).

Dessa forma, somos levados a concluir em consonância com o brocado jurídico que atesta que, muito embora algumas leis ou normas apresentem suas impropriedades e imperfeições, o ordenamento jurídico é um todo perfeito e incontestável. Em que pese a insuficiência de órgão fiscalizador da atividade em pauta, podemos observar que não será por falta de instrumentos jurídicos que esse setor poderá entrar em colapso: as normas existem, sendo necessário segui-las.

\section{CONSIDERAÇÕES FINAIS}

Evidencia-se a necessidade de regras jurídicas como forma de organizar e harmonizar a sociedade humana, do mesmo modo para regulamentar e ordenar as atividades mercantis e econômicas como o turismo e a hospitalidade, precipuamente no que tange ao seu desenvolvimento, regulação e subsídios, à proteção do patrimônio turístico, além da proteção do próprio turista e tomador deste produto e serviço.

Assim, torna-se claro o tratamento da legislação constitucional, bem como da legislação infraconstitucional ao tema, com destaque especial ao Código de Defesa do Consumidor como instrumento jurídico regulador das relações de consumo e de proteção ao consumidor e ao fornecedor.

Por tratar-se de universo diverso e compartimentado com diversas particularidades em relação a outros setores da economia, mas tratado por ampla e ordenada legislação, percebe-se 
que o turismo e a hospitalidade brasileira encontram-se devidamente conectadas com esses outros setores e com a globalização mundial, perseguindo seus importantes movimentos, normas regulamentadoras, princípios e tratados.

O presente estudo, desenvolvido com o intuito de incentivar o debate sobre os rumos do turismo e hospitalidade brasileira, considerando um aspecto importante - o jurídico, aspectos e segmentos -, conclui que o trabalho de regulamentação não é tarefa fácil, nem rápida, principalmente se formos tratar o turismo e hospitalidade não somente como uma atividade econômica, mas também como um fenômeno social que traz consequências importantes para as comunidades envolvidas.

Se por um lado tem-se a existência de legislação ordenadora dessas atividades, há que se considerar que a regulamentação excessiva igualmente poderá impedir melhorias na atividade pelo engessamento da livre iniciativa.

Em se tratando de um setor essencialmente privado, o turismo e hospitalidade precisam de liberdade para o desenvolvimento de suas atividades. Para alguns, a exigência de cadastro e certificação das empresas turísticas no Ministério do Turismo e outros organismos representa a burocratização da atividade ou mesmo, um entrave ao trabalho dos diversos empreendedores. Para outros, tal tratamento representa a homogeneização e profissionalização do setor com a sua colocação dentro dos parâmetros exigíveis pela nova ordenação mundial.

É mister concluir que um texto legal não tem o poder de revolucionar ou simplesmente alterar uma ordem social sozinho e que, em busca de objetivos, é necessário aos envolvidos aceitálo como legítimo.

Objetivamente, o Brasil possui um ordenamento jurídico lógico e organizado orientado para a organização e desenvolvimento deste importante setor da economia. Contudo, há a se fazer para que a atividade se desenvolva com excelência atendo padrões internacionais, sem olvidar as particularidades tipicamente brasileiras.

Agora, talvez seja o momento é de acompanhar e torcer pela concretização das normas e medidas previstas, que promoverá, por conseguinte, as transformações fáticas com relação ao turismo prometidas no texto legal. 


\section{REFERÊNCIAS}

BADARÓ, Rui Aurélio de Lacerda (Org.). Turismo e Direito: convergências. São Paulo: Editora Senac, 2006.

BADARÓ, Rui Aurélio de Lacerda (Org.). A Evolução da Legislação Turística Brasileira: o início do direito do turismo. 2007. Disponível em: <http:// www.aedmoodle.ufpa.br/

Evoluo_da_legislao_turistica_no_Brasil.pdf+\&cd=2\&hl=pt-BR\&ct=clnk\&gl=br>. Acesso em: 25 fev. 2015.

BADARÓ, Rui Aurélio de Lacerda. Hotelaria à Luz do Direito do Turismo. São Paulo: Editora Senac, 2014.

BRASIL. Lei $\mathbf{n}^{\circ}$ 6.505, de 13 de dezembro de 1977. [1977]. Disponível em:

<http://www.camara.gov.br>. Acesso em: 2 jan. 2015.

BRASIL. Lei n` 8.078, de 11 de setembro de 1990. [1990]. Disponível em:

<https://www.planalto.gov.br/ccivil_03/Leis/L8078.htm>. Acesso em: 14 nov. 2016.

BRASIL. Lei n 8.181, de 28 de março de 1991. [1991]. Disponível em:

<http://www.camara.gov.br>. Acesso em: 2 jan. 2015.

BRASIL. Lei $\mathbf{n}^{\circ}$ 10.683, de 28 de maio de 2003. [2003]. Disponível em:

<http://www.camara.gov.br>. Acesso em: 2 jan. 2015.

BRASIL. Regulamentação, Normalização e Certificação em Turismo de Aventura. Relatório Diagnóstico. Brasília, DF: Ministério do Turismo, 2005.

BRASIL. Lei $\mathbf{n}^{\circ} 11.771$ de 17 de setembro de 2008. [2008]. Disponível em:

<http://www.camara.gov.br>. Acesso em: 2 jan. 2015.

FERNANDES, Patrícia Verônica Nascimento Dias; SANTOS, Jonatas Oliveira dos. A normalização como insumo da documentação científica. In: SEMINÁRIO NACIONAL DE BIBLIOTECAS UNIVERSITÁRIAS, 24., Salvador, 2006. Anais... Salvador: UFBA, 2006.

INMETRO. Credenciamento. [2009]. Disponível em: <http://www.inmetro.gov.br/credenciamento/>. Acesso em: 2 abr. 2015.

LAVOR, Cecília Said de. Um Estudo sobre a Normalização e Certificação do Turismo no Brasil: situação atual e perspectivas. 2009. Disponível em:

<http://repositorio.unb.br/bitstream/10482/11005/1/2009_CeciliaSaiddeLavor.pdf >. Acesso em: 17 mar. 2015.

LENZA, Pedro. Direito Constitucional Esquematizado. 13. ed. São Paulo: Saraiva, 2009.

LONGANESE, Luiz André. Direito Aplicado à Hotelaria. Campinas: Papirus Editora. 2004.

MAMEDE, Gladston. Direito do Turismo Legislação Especifica Aplicada. São Paulo: Atlas, 2001.

NIETO, Marcos Pinto. Manual de Direito Aplicado ao Turismo. 4. ed. Campinas: Papirus Editora, 2004.

OLIVEIRA, Tassiana Moura de. A Lei do Turismo - Lei 11.771, de 17 de setembro de 2008: uma breve análise. Revista Turismo em Análise, v. 20, n. 2, p. 252-262, ago. 2009. Disponível em:

<http://www.revistas.usp.br/rta/article/view/14184>. Acesso em: 5 mar. 2015.

PEREZ, Amparo Seicho. Organização Mundial do Turismo. São Paulo: Roca, 2006.

RÉ, Juliana Pagotto. Hotelaria à Luz do Direito do Turismo. 2007. Disponível em: $<$ http://www.unimep.br/phpg/mostraacademica/anais/5mostra/backup/4/60.pdf $>$. Acesso em: 5 mar. 2015. 